\title{
Dünya oyunun gücünde uzlaştı şimdi bu gücü çocukların yararına kullanma zamanı: Hadi Türkiye...
}

\author{
The world agree on the power of the "Play": It is now time to use this \\ power for the benefit of children: Come on Turkey...
}

Belma Tuğrul ${ }^{1}$

\begin{abstract}
Öz: Çocukların nasıl daha kolay öğrenebileceklerine, nasıl daha sağlıklı bir büyüme ve gelişme sağlayabileceklerine ilişkin sorulan sorular bizi "oyun” la buluşturur. Çocuk oynuyorsa öğreniyor ve sağlıklı demektir. Aslında bu bir döngüdür, oyun oynadıkça çocuk daha sağlıklı olur ve öğrenme deneyimleri zenginleşir. Oyunun gücü çocuğun bütüncül gelişimine sağladığı katkılardan gelir. Çocuklar oyun oynama sürecinde yaşam becerileri; sosyal beceriler, araştırma becerileri, problem çözme becerileri, düşünme becerileri, iletişim becerileri ve kendi kendini idare etme ve yönetme becerileri konusunda deneyim sahibi olurlar. Bugün birçok dünya ülkesinin üzerinde emek harcadığı eğitim reformlarının temelini çocukların kendi hızlarında, uygun yöntemlerle kapasitelerini en üst seviyede kullanabilecekleri öğrenme firsatlarına sahip olabilmesi yönündeki çabalar oluşturmaktadır. "Oyun" bu çabaların ya da bir başka deyişle eğitim alanındaki sorunların mutlak çözümünde bilimsel olarak kanıtlanmış firsatlardan en önde gelenidir. Bu makale, farklı ülkelerde yapılan oyun temelli okul ve eğitim programlarının sonuçlarını paylaşmak üzere derlenmiştir. Ülkemizde de her firsatta oyunun pedagojik değerine vurgu yapılırken, uygulama alanında da somut çalışmalara dikkat çekmek hedeflenmiştir.
\end{abstract}

Anahtar Kelimeler: Oyun, çocuk, erken çocukluk dönemi, oyun kültürü

\begin{abstract}
The questions like how children learn easily, and how they can achieve a healthier growth and development bring us to the idea of "play". If a child plays, this shows that he/she is healthy and can learn things. In fact, it is a cycle, the more children play, the healthier the child becomes and the more their learning experiences become richer. The power of the play comes from the contributions that it provides for a child's holistic development. In the process of playing a game, Children gain valuable life skills, such as; social skills, research skills, problem solving skills, thinking skills, communication skills, and self-sufficiency and management skills. The educational reforms that many world countries are now working on essentially makes an effort to provide children with the opportunity to learn at their own pace, to use their capacities at the highest level with appropriate methods. "Play" is the most prominent of these efforts or, in other words, scientifically proven opportunities in the absolute solution of the problems in the field of education. This article is compiled to share the results of play-based school and educational programs in different countries. In our country, while emphasizing the pedagogical value of the play at every occasion, it was aimed to draw attention to concrete studies in the field of application.
\end{abstract}

Keywords: Play, child, early childhood, culture of play

\footnotetext{
${ }^{1}$ İstanbul Aydın Üniversitesi, Eğitim Fakültesi, Temel Eğitim Bölümü, serhatbelmatugrul@gmail.com
} 


\section{GİRIS}

Oyunun eğitsel değeri yüzyılımızın keşfi değildir. Çocuk gelişimi ve eğitimi ile ilgili olarak fikirleri halen kabul gören çok sayıdaki düşünür ve bilim insanından; Comenius, Locke, Rousseau, Pestalozzi, Froebel, Montessori, Rudolf Steiner, Freud, Piaget, Erikson ve Vygotsky’nin ileri sürdürdükleri görüşleri ve geliştirdikleri kuramlarındaki ortak nokta; çocuğun gelişimine, gereksinimine, ilgisine, yeteneğine ve yüksek yararına yönelik bir ortamda büyüme ve gelişmesinin sağlanmasıdır (Miller, Almon 2009; Fleer 2010). Örneğin; Pestalozzi ve Froebel çocuğun yaşamında oyunun ve doğa ile buluşmanın önemine vurgu yapmışlardır ve Froebel “oyunun kendisi başlı başına bir kazanımdır, bu nedenle ne öğretecekseniz ögretin ama bunu çocuğun en canlı olduğu oyun ortamında ögretiniz”, John Lock ise “derslerinizin daha çekici olmasını istiyorsanız çocuğun ilk yıllardaki oyun içgüdülerinden yararlanın” demiştir. Rousseau Emile kitabında ise "çocukluk hiç tanınmıyor, çocuğu tanıyın ve onun gereksinimi olan doğadan ve oyundan onu mahrum etmeyin” fikrini savunmuştur. Oyunun iyileştirici, geliştirici ve öğretici yönü onu güçlü kılmaktadır (Tuğrul, 2009; 2010; 2013). Vygotsky çocuğun soyut düşünme becerisinin temellerinin bu ilk sembolik temsil yeteneklerinin gelişmesi ve dil alanındaki ustalıklarıyla ilişkili olduğunu belirtmiş ve bu kazanımlar için de "oyunu" major belirleyici olarak referans almıştır. Oyun çocuğun iç dünyasını yansıtan bir araç olmakla birlikte aynı zamanda iç görü kazanmasında da etkili rol oynamaktadır. Çocuğun bu özelliklere sahip olması da doğrudan akademik başarının ve duygusal refahın belirleyicisi olarak görülmektedir (Whitebread, 2010, 2012). Özellikle çocukların yaygın bir şekilde oynamayı tercih ettikleri sembolik oyunun çocukların okuduğunu anlama ve soyut kavramları farkına varma ve matematik becerilerinin gelişimindeki katkıları vurgulanmıştır (Ailwood, 2010; Anita, 2006; Bodrova 2005; Catherine ve Susan, 2008; Johnson ve ark, 2005; Melinda, 2009).

Oyunu anlamak ve değer vermek, çocuğu anlamak ve değer vermek demektir. Bir çocuğu tanımanın ve anlamanın en güvenli yolu, oyunlarını gözlemektir. Çünkü çocuk, oyun sırasında olduğu gibidir. Plato bir çocuğu tanımak için bir yıl onunla birlikte olmak yerine bir saat onu oyun sırasında gözlemenin yeterli olacağını söyleyerek, oyunun çocuğu tanıma ve anlama yönündeki gücüne dikkat çekmiştir. Araştırmacılar oyunun sadece çocukluk yaşları üzerindeki olumlu etkileri ile yetinmemişlerdir, en az çocuklar kadar yetişkinlerin yaşantısında da oyunun değeri üzerine odaklanmışlardır. Bebeklik döneminden itibaren yeterince oyun oynama fırsatı bulan çocukların ileri yaşlardaki olumlu yönde gelişen sosyal - duygusal özellikleri ve okul başarıları da araştırmacıların dikkatini çekmiştir. Araştırmacılar, yetişkinlik yaşlarında oyuncu 
-eğlenceli- "playful”" olmanın entelektüel başarı ve duygusal olarak iyilik hali -duygusal refahile sonuçlandığını desteklemişlerdir (Whitebread, 2012). Oyun konusu sadece eğitim bilimlerinin dikkatini çekmemiştir. Örneğin; geçmişte ve günümüzde arkeologlar, tarihçiler, antropologlar ve sosyologlar yaptıkları araştırmalarında tüm zamanlarda ve tüm kültürlerde çocukların oyunlarına ve oyun araçlarına verdikleri önemi destekleyen çok önemli kanıtlara ulaşmışlardır. Oyunun zihinsel gelişim, üst bilişsel beceriler (metacognitive), sağlıklı ruh hali, dil becerileri, temsil etme, öz-düzenleme yeteneklerinin gelişmesine katkısının evrimsel, sosyolojik ve psikolojik kanıtları vardır.

Pam Jarvis ve Jane George (2013), oyunun çocukların okula karşı olumlu tutum geliştirmesindeki etkisinin dikkat çekici olduğunu ve okul dışındaki oyun olanaklarının da çocukların öğrenmeye devam etmesi için okuldan bağımsız firsatlar olarak kullanılması gerektiğini belirtmiştir. Araştırmacılar "çocukların sesini dinlersek oyunsuz okul olmaması gerektiğini hemen anlarız” demişlerdir (Akt: Brock, 2013). Çocuklar için oyun, yetişkin dünyasının tanımı ile "iş” e karşılık gelmektedir. İngiltere'de yapılan bir çalışmada annelerin tipik bir okul gününün ardından çocuklarına sordukları "bugün okulda ne yaptın?” sorusuna çocuklarının" oyun oynadık" yanıtını verdikten sonra annelerin "oyundan başka ne yaptığınızı soruyorum" vb şekilde çocuklarının yanıtından tatmin olmadıkları görülmüştür. Anneler çocuklarına ısrarla okulda "ne iş, ne faaliyet" yaptıklarını sorunca çocuklar da "işte oyun oynadık diyorum ya yarın da oynayacağız" yanıtını vermişlerdir. Çocukların oyunu iş olarak algılaması, aileleri kaygılandırmakta ve çocuklarının okulda bir şey öğrenmediklerini düşündürmektedir. Öğretmenler tarafından yönlendirilen ve hatta akademik bilgi ağırlıklı etkinlikler, aileleri daha çok memnun etmekte ve güven vermektedir (Fleer, 2010, 2013). Oyuna verilen önem ve oyunun ne olduğuna ait görüşler, çocuklara sağlanan oyun olanaklarını da doğrudan etkilemektedir. Yetişkin dünyası oyunu sadece boş zaman geçirilen bir eylem olarak kabul ettiği sürece, çocukların evde ve okulda oyundan istenilen seviyede yararlanabilmeleri mümkün görünmemektedir.

Pam Jarvis 2013'te oyunun uzun vadede insan psikolojisi üzerinde yarattı̆̆1 olumlu etkileri incelemiş ve oyun ile gelişim arasındaki bu olumlu ilişkinin, okul programlarına oyunun dâhil edilmesini zorunlu kıldığını belirtmiştir (Akt: Brock, 2013). Brock, 2013'deki çalışmasında 36 yaşlarındaki çocuklara sağlanan nitelikli oyun desteğinin çocukların ilkokula hazır hale gelmesinde çok etkili olduğunu ancak bu süreçte öğretmenlerin eski geleneksel öğretmenlik tutumlarından vazgeçip oyun pedagojisini benimsemeleri gerektiğini belirtmiştir. Brock, bu durumun tamamen erken çocukluk felsefesini yeniden gözden geçirmekle ilgili olduğuna da 
dikkati çekmiştir. Erken çocukluk eğitimi ile okula geçişin bütüncül bir anlayış içinde ele alınmasında oyunun bütünleştirici gücünden yararlanmak gerekmektedir. Sylvia Dodds ise 2013'deki çalışmasında sadece küçük çocukların değil 6 ile 11 yaşlar arasındaki çocukların da oyun müfredatı içinde olması gerektiğini, çocukların "play based roots" oyun temelli bir öğrenme ağı kurabildiklerini belirtmiştir. Çocukların oyun temelli müfredatla öğrendiklerini bir alandan diğerine transfer edebilmelerinin mümkün olduğunu söylemiş ve bu öğrenme linkini, çocuğun gelişimi için büyük bir fırsat olarak görmüştür. Ayrıca Dodds, farklı kültürlerden gelen çocukların birbirleriyle kaynaşmalarında ve öğrenen ile öğreten arasında oyunun uzlaştırıcı yönüne ve sınıftaki özel gereksinimi olan çocuklar için kendi öğrenme yollarını bulmaları açısından çok sayıda olanak yarattığını da belirtmiştir (Akt: Brock, 2013).

İngiltere'de erken öğrenme hedefleri içinde çocukların öğrenme sürecinde çocukların kendilerinin başlattığı ve yönettiği oyunlara ve yapılandırılmış oyunlara daha fazla yer verilmesi gerektiği vurgulanmıştır. Çin ve Japon toplumlarında da çocuğun oyuna olan gereksinimi dikkate alınarak okullarda oyun zamanları ayarlanmıştır. Ancak bu oyunların daha çok içerde ve dışarıda oynanan geleneksel grup oyunları ve son yıllarda da giderek artan teknolojik araçlarla oynanan oyunlar olduğu rapor edilmiştir. Aileler, milenyum çocuklarının teknolojik gelişmelere en erken yaştan itibaren uyum sağlaması gerektiğini savunmaktadırlar (Sayeed ve Guerin, 2010). Birçok bilimsel çalışma öğrenmenin gücünün "özellikle erken çocukluk yıllarında" oyunun gücüyle birlikte artış gösterdiğini desteklemektedir (Henniger, 2009; Pasek ve ark 2009; Wood \& Attfield, 2005). İngiltere'de ulusal müfredatın yeniden yapılanması sürecinde oyun, erken çocukluk ve ilkokul seviyesinde daha ağırlıklı olmak üzere tüm öğrenim kademelerinde sisteme dâhil edilmeye çalışılmış ve oyun temelli eğitimin, sistemin çıktılarını olumlu yönde etkileyeceği savunulmuştur (Brocks ve ark., 2013). Yani erken çocukluk eğitimi desteklenirse çocukların doğal olarak oyun oynama gereksinimlerini karşılayacakları varsayılmaktadır.

Singapur'da öğretmenlere kendi çocukluk yıllarındaki oyun yaşantıları sorulmuştur. "Play memory" olarak bilinen bu çalışmada, öğretmenler kendi çocukluk yıllarında zamanlarının çoğunu oyun oynayarak geçirdiklerini, açık alanlarda çamur, su, toprak gibi doğal oyun malzemelerini kullandıklarını, farklı yaşlardaki arkadaşlarıyla oynayabildiklerini ancak günümüzdeki çocukların oyuna ayıracak zamanlarının azaldığını ve çocukların doğal oyunlardan çok hazır oyuncaklarla oynadıklarını belirtmişlerdir. Öğretmenler ailelerinin oyunla ilgili güvenlik kaygılarının çok düşük seviyede olduğunu çünkü kendilerinden büyük ve küçük çocuklarla birlikte oyun oynayabildiklerini belirtmişlerdir (Fleer, 2014). Bodrova 2008'de 
yaptığı çalışmasında günümüz çocuklarının doğal ve doğadan şeylerle oynamaktan uzaklaştığını ve artık oyuncak tercihlerinde hazır oyuncakları kullanmaya istekli davrandıklarını belirtmiştir. Bodrova çocukların doktor rolünü kendisi yerine oyuncak olan doktor bebeğine verdiğini gözlemlemiştir. Bu ve bunun gibi yapılan çok sayıdaki araştırma çocukların oyun tercihleri ve oyun araçları değiştikçe oyundan yararlanma boyutları da değişmektedir. Bu değişim ise maalesef olumlu yönde bir değişim olarak rapor edilmemektedir. Farver ve arkadaşları 1995'de Anglo American ve Korean American anaokulu çocukları ve öğretmenleri ile yaptıkları araştırmalarında öğretmenlerin oyuna verdiği değer, oyuncu-oyun dostu öğretmen olması, çocuklara sağladığı oyun olanaklarını (materyaller, çevre düzenlemesi ve oyuna dayalı öğrenme) olumlu yönde etkilemiştir. Swedener ve John (1989) ise ailelerin çocuklarının oyunlarına karşı olumlu tavır içinde olmalarının çocukların hayali oyunlarını ve yaratıcı oyunlarını olumlu yönde desteklediğini belirtmişlerdir (Akt: Fleer, 2013).

Benjamin Bloom (1964), kapsamlı çalışmasında 18 yaşına kadar öğrenilen bilgilerin \%80 inin 8 yaşına kadar kazanıldığını ve oyunun bu dönemde çok önemli olduğunu vurgulamıştır. Bloom aynı çalışmasında çocukların bu sekiz yıllık yaşam evresinde de ilk dört yılın çok kritik olduğunu ve bu dönemde çocukların oyun çocuğu olması nedeniyle bu oranın \% 50 ye ulaştığını belirtmiştir. 1960 ile 1970 yılları arasında İngiltere' de okullarda oyun bir öğrenme aracı olarak kullanılmış ve bu eğitim modeli çok desteklenmiştir. Lokal düzeyde oyuncak kütüphaneleri açılmış, oyun birlikleri -play association- toplum gönüllüleri ile birlikte okulda ve toplum merkezlerinde oyunu destekleyen işbirlikleri içine girilmiştir. Uluslararası düzeyde ise 1987'de Stockholm da, 1990 yılında da Tokyo'da yapılan International Association of Right of the Child to Play konferanslarında oyuna bir çocukluk hakkı olarak vurgu yapılmıştır (Akt: Sayeed, Guerin 2010). Wong ve Fleer (2012)'de Hong Kong ve Avustralya'lı ailelerle yaptığ araştırmasında ailelerin çocuklarıyla oyun oynamaktan çok, onları organize olmuş etkinliklere yönlendirmede daha istekli olduklarını ve ailelerin oyundan çok bu tip (tenis, yüzme, müzik gibi) etkinliklerden daha fazla yarar sağladıklarına inandıklarını tespit etmişlerdir. Bu aileler çocuklarının ev ödevi yapmalarını onları oyun oynamaktan uzaklaştırmanın bir yolu olarak gördüklerini de belirtmişlerdir (Fleer, 2013). Fisher ve ark 2008'de ailelerin çocukları için eğitim kasetleri, standart testlerden oluşan çalışma kitaplarını oyuna tercih ettiklerini bulmuşlardır.

Oyunun okulda değil, evde ya da özel oyun alanlarında oynanabileceği düşüncesi, oyunun pedagojik değerinin anlaşılmadığının bir diğer kanıtıdır. Moyles 2010'da İngiltere'deki ilkokullarda öğretmenlerin oyuna yeteri kadar ilgi göstermemesi ve oyunu ders programlarıyla 
bütünleştirememelerinin nedenleri üzerinde çalışmıştır. Öğretmenler sınıflarında oyun oynayan çocukları gören ailelerin "bu öğretmenler çocuklarımıza bir şey öğretmiyor sadece oyun oynuyorlar" şeklinde kendilerine ve yöneticilere baskı yaptığını belirtmişlerdir. Bunun yanı sıra öğretmenler mesleki gelişim kurslarında oyunla ilgili yeterince bilgilenmediklerini, oyunun değerini anaokul öğretmenleri kadar bilmedikleri için oyuna güvenmekte tereddüt ettiklerini, oyun ve öğrenme ile ilgili ilişkiyi vurgulayan araştırmaların yetersiz olduğunu, politikacıların uluslar arası seviyelerde yapılan sınavlarda ülkenin sıralamasını önemsemeleri nedeniyle akademik müfredata daha fazla önem verdiklerini rapor etmişlerdir. Ayrıca öğretmenler EYFS (Early Years Foundation Stage) nin çocukların okula başlama yaşı ve öğrenim kademeleri arasındaki geçişlere yönelik kararsızlıklarının ilkokul programlarında yaşanan memnuniyetsizliklerini de etkilediğini belirtmişlerdir. Lillard ve arkadaşları (2012), Pinkham ve arkadaşları (2012) yaptıkları çalışmalarında oyun ve öğrenme arasındaki pozitif korelasyonun yeni bir araştırma konusu olmadığını, 40 yıldır yapılan çalışmalarla bu ilişkinin doğrulandığını belirtmişlerdir. Araştırmacılar çocukların doğrudan aktarılan bilgiler yerine, kendi deneyimleriyle ve yordamaya dayalı tecrübelerle daha kolay ve kalıcı öğrenebildiklerini vurgulamışlar ve bunun için oyunun en etkili öğrenme yolu olduğunu belirtmişlerdir. 2009 yılında ise Brock, İngiltere'deki çalışmasında, öğretmen adaylarının oyun hakkında olumlu fikirlere sahip olduğunu ancak öğretmenlerin uygulama sırasında oyunla ilgili sorunlar yaşadıklarını rapor etmiştir. Bu durum öğretmenlerin hizmet içi eğitim gereksinimlerine dikkatleri çekmektedir.

Nancy Carlsson'un 30 yılı aşkın süredir kırsal ve kentsel kesimde çalışan anaokul öğretmenleriyle yaptığ 1 görüşmeler ve araştırmalar göstermiştir ki erken çocukluk yaşlarından başlayarak ilköğretim seviyesinde de giderek artan bir şekilde oyundan mahrum kalmaktadırlar ve okullar giderek "çocuk merkezli ve oyun temelli” olmaktan uzaklaşmaktadır. Bu durum çocukların kısa ve uzun süreli gelişim süreçlerinde telafi edilmesi güç olan gelişimsel engeller doğurmaktadır. Duygusal, sosyal ve zihinsel alt yapının oluşması ve korunması oyun firsatı içinde doğal ve çok sağlam bir şekilde atılabilmektedir. Oyundan mahrum kalan çocuklar, ilerleyen yaşlarında zamanında ve yeterince karşılanmayan bu gereksinimlerinin açı̆̆ını çeşitli akademik ve sosyal sorunlarla yansitmaktadırlar ( Miller ve Almon, 2009).

Özetle yukarıda sunulan araştırmalardan da anlaşıldığı üzere oyun ve öğrenme, oyun ve sağlık (beden ve ruh sağlı̆̆ ) arasındaki ilişki, çocukların oyun haklarının okul ve sosyal yaşamlarında korunması konusuna dikkat çekmektedir. Dünyanın her yerinde farklı kültürlerde sürdürülen oyun araştırmalarının “oyun, öğrenme ve sağlıklı büyüme, gelişim bağlamındaki” sonuçları 
oyunun gücünü evrensel düzeyde kanıtlamaktadır. Çocukların oyuna olan evrensel ilgisi, kültürler arası araştırmalar yapmaya çok müsait bir ortam yaratmaktadır. Çocukların oyuna ilgisi ve oyun gereksinimi evrensel bir anlam taşısa da, çocukların sahip olduğu olanaklar kültürler arası farklılık göstermektedir. O halde biz bilim insanları başta olmak üzere kendi ülkemiz koşullarında oyundan daha üst seviye yararlanmak için neler yapabiliriz? Hadi Türkiye....

\section{KAYNAKLAR}

Ailwood, J. (2010). Playing with Some Tensions; Poststructuralim, Foucault and Early Childhood Education. In L Broker\& S.Edwards ( Eds). Engaging Play. Maidenhead: Open University Pres, (210-222).

Anita, E. (2006). Scripted Curriculum: Is It A Prescription For Success?. Childhood Education; Http://Findarticles.Com/P/Articles/Mi Oa3614/Is 200610/Ai N17189994.

Bodrova, E., \& Leong, D. J. (2005). Uniquely preschool. Educational Leadership, 63(1), 4447.

Bodrova, E., ve Deborah J. L. (2008). Developing Self-Regulation in Kindergarten. Can We Keep All The Crickets in the Basket? Young Children, March, 1-3.

Brock, A., Dodds,S., Jarvis,P., ve Olusoga,Y. (2013). Persfectives On Play : Learning For Life. New York: Pearson Education Limited.

Catherine E. S., ve Susan B. V.H. (2008). Editors, National Research Council of the National Academies, Early Childhood Assessment: Why, What, and How, National Academies Pres. 10; http://books.nap.edu/openbook.php?isbn=030912465.

Fleer, M (2013). Play in the Early Years . New York: Cambridge Unv Press.

Fleer, M (2014). Theorising Play in the Early Years. New York: Cambridge Unv Press.

Fleer, M. (2010). Early Learning and Development : Cultural-Historical Conceps In Play. Melbourne : Cambridge Unv Press.

Henniger, L.M. (2009). Teaching Young Children an Introduction. New Jersey: Person Education Inc.

Johnson,E.J., Christie,J.F., ve Wardle,F. (2005). Play Development and Early Education. Boston: Pearson Education,Inc.

Lillard, A. S., Lerner, M.D., Hopkins, E.J., Dore, R.A., Smith, E.D., ve Palmquist, C.M. (2012). The Impact of Pretend Play on Children's Development: A Review of the Evidence. Psychological Bulletin. Advance Online Publication. Doi: 10.1037/A0029321.

Melinda, W. (2009). The Serious Need For Play. Scientific American Mind. Http://Www.Sciam.Com/Article.Cfm? İd=The-Serious-Need-For-Play\&Page=5.

Miller, E., ve Almond, J. (2009). Crisis in the Kindergarten: Why Children Need to Play in School? College Park: Alliance for Childhood.

Moyley, J. (2010). Practitioner Reflection on Play and Playful Pedagogies. In J Moyles (Ed). Thinking About Play Developing A Reflective Apporoach, Maidenhead. Open University. 
Pasek, K.H., Golingof, R.M., Berk, L.E., ve Singer, D. (2009). A Mandate for Playful Learning in Preschool: Compiling The Scientific Evidence. Oxford University.

Pinkham, A. M., Kaefer, T., ve Neuman, S. B. (2012). Knowledge Development in Early Childhood: Source of Learning and Classroom Implications. New York: Guilford Press. Sage Pub.

Sayeed, Z., ve Guerin,E. (2010). Early years play: A Happy Medium for Assesment and Intervention. David Fulton Publishers Ltd.

Tuğrul, B. (2009). Okulöncesi Ĕgitimde Kullanılan Öğretim Yöntemleri ve Teknikleri. Özel Öğretim Yöntemleri Edt: Prof. Dr. Mustafa Sağlam. Anadolu Üniversitesi Yayını No:1851, Açık Öğretim Fakültesi Yayını No: 966. Ekim.

Tuğrul, B. (2010). Çocuk Dostu Öğrenme Ortamları, Okulda Yenilenme. 215- 221. Antalya: Özel Okullar Birliği Derneği Yayını.

Tuğrul, B. (2013). Çocukta Oyun Gelişimi. Neriman Aral, Ümit Deniz, Adnan Kan (Ed.), Öğretmenlik Alan Bilgisi: Okul Öncesi Öğretmenliği. 245-269. Ankara: Alan Bilgisi.

Whitebread, D. (2010). Play, Metacognition and Self-Regulation. In P. Broadhead, J. Howard And E. Wood (Eds.). Play And Learning In The Early Years. London: Sage.

Whitebread, D.(2012). The Importance of Play. A Report On Value Of Children's Play. A Report on the Value of Children's Play with a Series of Policy Recommendation. Written for Toy Industries of Europe (TIE).

Wood, E., \& Attfield, J. (2005). Play, learning and the early childhood curriculum. London:Sage. 